\title{
HIV Diagnosis in Resource Constrained Setting: How Good Is the Current Algorithm?
}

\author{
Nayana Ingole, Purva Sarkate, Supriya Paranjpe, Rahul Sarode, \\ Sameer Shinde, Preeti Mehta \\ Department of Microbiology, Seth G S Medical College and KEM Hospital, Parel, Mumbai, India \\ Email: nayanaingole@gmail.com
}

Received 21 September 2013; revised 21 October 2013; accepted 28 October 2013

Copyright @ 2014 by authors and Scientific Research Publishing Inc.

This work is licensed under the Creative Commons Attribution International License (CC BY). http://creativecommons.org/licenses/by/4.0/

(c) (i) Open Access

\section{Abstract}

Background: The conventional HIV testing algorithm in most of the developed countries consists of two tests: an HIV enzyme immunoassay capable of identifying HIV-1 and HIV-2 antibodies and a confirmatory HIV-1 Western blot or immunofluorescence assay. However, the current algorithm for HIV diagnosis in India uses three sequential antibody assays. There has always been doubt regarding the benefits of this algorithm. Objective: To determine the utility of the current diagnostic algorithm and to find out the proportion of indeterminate or discrepant results. Methods: Retrospective analysis of HIV antibody testing data was carried out over a period of five years after institutional ethics committee approval. The specimens positive with the screening test and negative with both the supplemental tests were labeled as discrepant. Specimens positive with any of the two tests (screening and one of the supplemental tests) and negative with the remaining supplemental test were labeled as indeterminate. These indeterminate specimens were confirmed by immunoblotting. Results: A total of 141,296 samples were tested. Of these, $71(0.05 \%)$ samples were indeterminate and $292(0.21 \%)$ were discrepant. Western blot was done on 60 indeterminate samples of which $10(16.67 \%)$ were positive for HIV 1 antibodies, 14 $(23.33 \%)$ were negative for HIV antibodies and $36(60 \%)$ had indeterminate result. Conclusion: In view of the low numbers of indeterminate and discrepant results, the current algorithm appears to be appropriate in our resource constrained setting. However, the algorithm for HIV testing should also include DNA PCR testing facility to resolve western blot indeterminate results.

\section{Keywords}

HIV; Indeterminate; Discrepant; Rapid Tests; Western Blot; Algorithm 


\section{Introduction}

The HIV testing strategies and relevant HIV testing algorithms of the National AIDS Control Organization (NACO), Government of India recommend the sequential use of three different HIV antibody assays for the diagnosis of HIV infection [1]. Commonly used tests for the same are rapid tests. Rapid HIV tests come in ready-to-use kits, which require no additional reagents or special equipment, and are reported to detect all subtypes with similar sensitivity and specificity. Most assays can be completed in a few easy steps, giving visual results in less than 20 minutes. Hence, report can be issued to the patient/client on the same day. These tests also have the added advantage that no special training or infrastructure is required for carrying out the same and are comparatively cost effective. High sensitivity tests are preferred for screening, while supplemental tests ideally have high specificity.

In contrast, the conventional HIV testing algorithm in most of the developed countries consists of two tests: an HIV enzyme immunoassay (EIA) capable of identifying HIV-1 and HIV-2 antibodies and a confirmatory HIV-1 Western blot or immunofluorescence assay (IFA) [2] [3]. These tests are comparatively more expensive and required specialized training, infrastructure and take more time.

However, there has always been doubt regarding the benefits of the three sequential tests algorithm. Also, when the results of the screening and supplemental tests are not the same (discrepant) or are indeterminate, the HIV infection status of the individual is determined through use of additional tests. These include a Western Blot assay, a Line Immuno assay, an enzyme-linked immunosorbent assay (ELISA) test for detection of antibodies and/or antigen, HIV DNA PCR and HIV-RNA viral load testing [4] [5]. NACO recommends the use of Western Blot assay/Line Immuno assay, for which the sample has to be referred to the National reference laboratory (NRL). Indeterminate results hinder clinical decisions, create more work, take up more resources in laboratories, and cause inappropriate anxiety to patients or even undesirable consequences [6] [7]. Hence, the present study was conducted to determine the utility of the current diagnostic algorithm in correctly identifying HIV infections and to find out the proportion of indeterminate or discrepant results at our centre over a period of five years.

\section{Methods}

A retrospective analysis of data was carried out for a period of five years from 2008 to 2012 after obtaining institutional ethics committee approval. All patients/clients including direct walk in clients, patients referred from outpatient department (OPD), indoor patients and pregnant women coming for ante-natal check-up were included in the study. HIV antibody testing was done as per strategy III of NACO for diagnosis of HIV [1]. One sample was collected per patient. The patients/clients were classified as HIV positive, HIV negative, HIV discrepant and HIV indeterminate based on their test results (Figure 1). All specimens were first tested with a screening test with a high sensitivity (as per supply from NACO). Samples non-reactive by this test were reported as negative. Samples reactive with the first test were subjected to $2^{\text {nd }}$ and $3^{\text {rd }}$ supplemental tests (immunochromatography and immunofiltration rapid tests as per NACO supply) which were more specific. The order of sequential antibody assays was the same in all the samples tested. Specimens which were reactive with all the three tests were reported as positive. Specimens which were positive with the screening test and negative with both the supplemental tests were labeled as discrepant. Specimens which were positive with any of the two tests (screening and one of the supplemental tests) and negative with the remaining supplemental test were labeled as indeterminate. All patients/clients diagnosed as HIV indeterminate/discrepant were included in the study. The route of transmission for HIV indeterminate and discrepant patients was analysed. The indeterminate samples were sent to National Reference Laboratory for immunoblotting, the results of which were considered final and reported to the patients/clients. To label a sample as HIV-1 positive by western blot, detection of at least two env bands (gp 160/gp 41 and gp 120) and either gag (p17/p24/p55) or pol (p31/p51/p66) was necessary. The samples in which any viral specific bands were present but did not meet the criteria for HIV-1 positivity were reported as western blot indeterminate.

\section{Results}

A total of 141,296 samples were tested for HIV antibodies over a period of five years. Out of these 71 (0.05\%) samples were indeterminate for HIV antibodies and were subjected to immunoblotting (Table 1). 


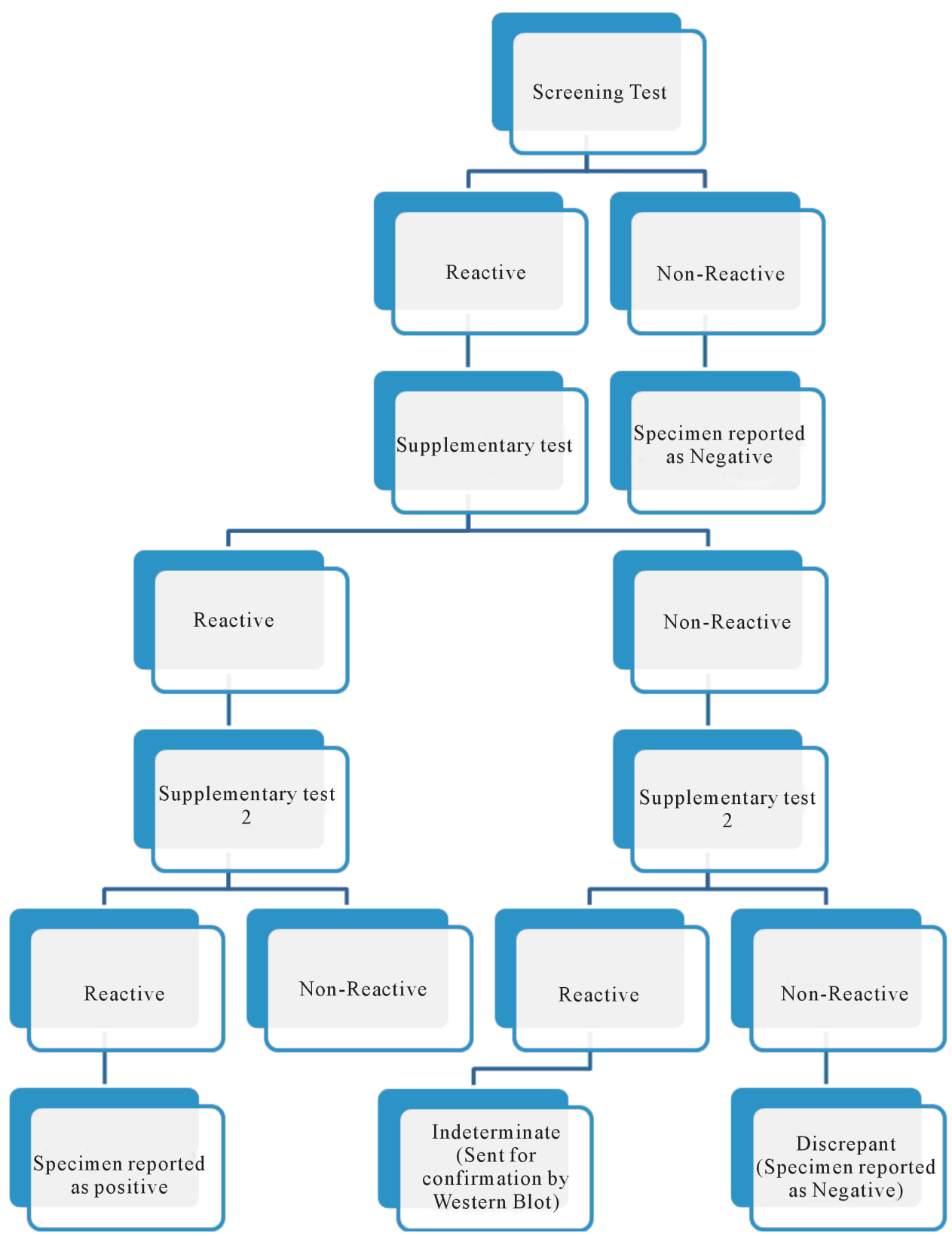

Figure 1. Algorithm for HIV diagnosis.

Table 1. Results of samples tested over a period of 5 years.

\begin{tabular}{ccccc}
\hline \multirow{2}{*}{ Year } & No. of Samples tested & \multicolumn{3}{c}{ Result } \\
\cline { 3 - 5 } & & Positive & Indeterminate & Discrepant \\
\hline $\mathbf{2 0 0 8}$ & 24125 & $2432(10.08 \%)$ & $10(0.04 \%)$ & $88(0.37 \%)$ \\
$\mathbf{2 0 0 9}$ & 23305 & $1923(8.25 \%)$ & $6(0.03 \%)$ & $73(0.31 \%)$ \\
$\mathbf{2 0 1 0}$ & 29460 & $1896(6.43 \%)$ & $13(0.04 \%)$ & $45(0.15 \%)$ \\
$\mathbf{2 0 1 1}$ & 29793 & $1757(10.69 \%)$ & $19(0.06 \%)$ & $37(0.12 \%)$ \\
$\mathbf{2 0 1 2}$ & 34613 & $1624(4.69 \%)$ & $23(0.07 \%)$ & $49(0.14 \%)$ \\
Total & 141296 & $9632(6.81 \%)$ & $71(0.05 \%)$ & $292(0.21 \%)$ \\
\hline
\end{tabular}


Of the 71 indeterminate samples, 17 (24\%) were less than 15 years of age. 13 (18.3\%), 14 (19.7\%), 15 (21.13\%) and $12(16.9 \%)$ were in the age group of $15-24,25-34,35-49$ and $\geq$ to 50 years respectively. 35 (49.3\%) were males and remaining were females. Nine clients were pregnant. The route of exposure was heterosexual in 54 (76\%) clients and vertical in 17 (24\%) clients.

Of the 71 indeterminate samples, western blot (WB) was done on 60 samples. 11 samples could not be sent for WB as the sample quantity was insufficient and patients did not come for follow up.

Of the 60 samples which were tested by WB, 10 (16.67\%) were positive for HIV 1 antibodies. 14 (23.33\%) were negative for HIV antibodies and 36 (60\%) had indeterminate result (WBi). p24 band was positive in 66.67\% (24/36) and gp band in 160 in 50\% of the WBi samples.

Of the total 141,296 samples tested, dot immunoassay was used as the screening test in 112,597 (79.7\%) samples and Immunochromatography in 28,699 (20.3\%). In case of all 14 samples which were reported as negative by western blot, the first test was immunochromatography. Dot immunoassay was the screening test in all the 10 positive samples by western blot.

Discrepant results were seen in $0.21 \%(292 / 141,296)$ of the samples which were reported as negative. On comparison between the two screening tests it was seen that Dot immunoassay yielded discrepant results in $0.21 \%$ $(238 / 112,597)$ of the samples whereas Immunochromatography in $0.19 \%(54 / 28,699)$.

\section{Discussion}

HIV/AIDS is a major concern of health care professionals all over the world. NACO recommends following "3C"s for the diagnosis of HIV infection namely Counseling (both pre- and post-test), Consent (written and informed) and Confidentiality. Government of India under National AIDS Control Program (NACP) has established multiple Integrated Counseling and Testing centers (ICTCs) across India as a key entry point for HIV related services. Since the first case was detected in India in 1986 the epidemic has seen many changes over the last 27 years. Currently, because of the increased awareness about the disease created through sustained efforts, though the number of tests performed for HIV diagnosis has increased, the positivity is decreasing (Table 1).

In most of the developed countries, the conventional HIV testing algorithm consists of two tests: an HIV enzyme immunoassay (EIA) capable of identifying HIV-1 and HIV-2 antibodies and a confirmatory HIV-1 Western blot or immunofluorescence assay (IFA) [2] [3].

However, due to resource and technical constraints, NACO recommends Strategy/Algorithm III for the diagnosis of HIV infection wherein the patient's blood specimen is tested by three serial antibody tests. Western Blot is done as a supplemental test only to resolve indeterminate results and not for confirmation of HIV status. Reported causes of indeterminate or discrepant rapid test results include early HIV infection [8]-[12] and false positive reactions due to malaria, pregnancy, syphilis, hepatitis B or endemic infections [13]-[17].

There has always been doubt regarding the benefits of this algorithm. However, in the present study indeterminate results were obtained in only $0.05 \%(71 / 141,296)$ of the total samples tested. A study by Thakral et al. in a study on blood donors had similar results (indeterminate results in $0.06 \%$ of samples) [18]. Also, discrepant results were seen in only in $0.21 \%$ of the samples. Hence, considering the diagnostic accuracy of three serial rapid tests used for testing the huge number of samples in the present study, the current algorithm used for HIV diagnosis in India under NACP appears to be appropriate for use in resource and technical constrained settings.

As per the strategy, the patients with discrepant result were issued a negative report and were not followed up and are a limitation of the study. However, Boeras et al. in their study on couples with indeterminate and discrepant result have reported that follow up testing is generally not necessary for individuals with screening test positive and second and third test negative and a negative partner [19].

At ICTC patients/clients are issued reports on the same day but in case of indeterminate results, the sample has to be sent to the higher reference laboratory for western blot; the result of which may take up to two weeks. HIV infection has a tremendous psychosocial impact. The stigma of being informed about HIV positive status creates personal and family rifts. It is very stressful for the client to await the final report. In India under NACP III, Western blot is the only option available to resolve cases which are indeterminate by rapid tests.

In the present study, even WB could not solve the problem of indeterminate status in $60 \%$ of the cases. The reported causes of indeterminate WB (WBi) result include systemic lupus erythematosus, rheumatoid factor, leprosy, post-measles virus infection, elevated bilirubin, polyclonal gammopathies, hemodialysis, autoimmune diseases, malignancies, urologic disorders, sexually transmitted diseases, and multiple blood transfusions [20]- 
[24]. However, we could not find any correlation of the indeterminate rapid or WB results with respect to age, gender, route of exposure and/or clinical condition of the patient.

The prime concern with WBi result as seen in $60 \%$ of patients in the present study is obviously the derived uncertainty in decision making for diagnosis, and hence, the ultimate objective in managing WBi results is to enable the differentiation of a true infection from nonspecific reactions. Currently, these patients have no other choice left than to do repeat testing after three months. However, the clients when asked to come for repeat testing, even after pre and post test counseling are lost to follow up. There are tests which can be done to establish diagnosis in WBi cases such as DNA PCR, RNA PCR and p24 antigen detection. Under NACO, DNA PCR is available free for early infant diagnosis of infants born to HIV positive mothers. Efforts can be made at the national level to make this test available for patients with indeterminate results free of cost. This would reduce the stress on the part of patients and will help in better management of these patients.

Sethoe et al. has reported that, no true case of sero conversion was evident in follow-up studies after a confirmation of negative results by PCR methods among the 26 samples from 23 individuals having screened positive but with WBi results [25]. Various long term follow-up studies have also revealed no evidence of HIV infection of healthy individuals who had persistent WBi results [26]-[30]. The CDC has recognized the existence of WBi results in low prevalence cohorts and has implemented guidelines for designating those individuals negative when no risk factors were involved and no changes in immune reactivity profiles were obtained with follow up testing [31].

Hence, in our scenario till there is a change in the strategy for indeterminate test results, it is appropriate to propose that in a patient with no known risk factors, a WBi result can be treated as negative if it is not accompanied by positive molecular test result.

Out of the 71 indeterminate samples, nine belonged to pregnant females enrolled under the PPTCT program. WB could be done for eight of these samples. Indeterminate results were obtained in 6/8 samples (75\%), and 2/8 (25\%) were negative by WB. This is expected as pregnancy is a known cause of false positive antibody results. However, as per Indian culture, many pregnant females go to their maternal place for delivery which makes it difficult to trace them in case of indeterminate results. Under the PРTCT program there are no set guidelines for procedure in case of consistent indeterminate results in pregnancy or in women with indeterminate result presenting directly in labour. Hence, tests which can resolve this indeterminate status will go a long way not only in protecting the unborn baby against HIV infection by timely prophylaxis but also in alleviating the stress of the woman and her family during her pregnancy.

Under the NACP, the test supplied to all the ICTCs in India usually has Dot immunoassay as the principle of the screening test and Immunochromatography \& Immunofiltration as principle of the supplemental tests. Rarely, the screening and supplemental tests have the same principle; but in that case they have different antigens.

In case of all the ten samples which were negative by western blot, both the screening test and the first supplemental test were Immunochromatography assays with different antigens and were reactive while the second supplemental test (immunofiltration assay) was non-reactive. In six of these ten samples, additional 4th (immunofiltration) and $5^{\text {th }}$ (ELISA) tests were also done in the reference laboratory, which were also negative in all samples. From these findings it appears that tests utilizing the principle of immunochromatography are sensitive and can be used as screening tests. However, it is likely to give more false positives if two out of the three rapid tests are based on the same principle even if they use different antigens.

Notably, the band for reactivity to p24 viral protein has been reported to be the most frequently occurring band among all the WBi patterns regardless of cohorts or study settings [23] [32] [33]. One of the possible suggested reasons for this could be that, the auto antibodies cross reacting with p24 are seen in autoimmune diseases like SLE [20] [21]. Anti-gp120/gp160 bands are reported to appear much less frequently and occurrences are more likely to be associated with the HIV-1 high-risk group [23] or with individuals having silent infection [34]. These findings correlate with our study where p24 band was seen in 66.67\% (24/36) and gp160 in 50\% (18/36) of the WB indeterminate samples.

\section{Conclusion}

To conclude, the current algorithm used for diagnosis of HIV infection appears to be appropriate in our resource and technical constrained setting. Serial tests used for antibody testing should preferably have different princi- 
ples rather than different antigens to reduce false positivity. For better management of patients with indeterminate results, counseling services should be strengthened to prevent loss from following up. Also, efforts should be made to provide DNA PCR testing facility free of cost to resolve WBi result in our national HIV testing policy.

\section{References}

[1] Guidelines on HIV Testing (2007) National AIDS Control Organisation, Ministry of Health and Family Welfare, Government of India.

http://naco.gov.in/upload/Policies\%20\&\%20Guidelines/5-GUILDELINES\%20FOR\%20HIV\%20TESTING.pdf

[2] Centers for Disease Control and Prevention (2009) HIV Testing Implementation Guidance for Correctional Settings. http://stacks.cdc.gov/view/cdc/5279

[3] Mounier-Jack, S., Nielsen, S. and Coker, R.J. (2008) HIV Testing Strategies across European Countries. HIV Medicine, 9, 13-19. http://dx.doi.org/10.1111/j.1468-1293.2008.00585.x

[4] Ren, A., Louie, B., Rauch, L., Castro, L., Liska, S., Klausner, J.D., et al. (2008) Screening and Confirmation of Human Immunodeficiency Virus Type 1 Infection Solely by Detection of RNA. Journal of Medical Microbiology, 57, 1228-1233. http://dx.doi.org/10.1099/jmm.0.2008/002386-0

[5] WHO/CDC/APHL (2002) Guidelines for Appropriate Evaluations of HIV Testing Technologies in Africa. Geneva. http://whqlibdoc.who.int/afro/2002/a82959 eng.pdf

[6] Roy, S., Fitz-Gibbon, L., Spira, B., Portnoy, J. and Wainberg, M.A. (1987) False-Positive Results of Confirmatory Testing for Antibody to HIV-I. CMAJ, 136, 612-614.

[7] Syed Iqbal, H., Balakrishnan, P., Solomon, S.S., Murugavel, K.G., Kumarasamy, N., Vidya, S., et al. (2005) HIV 1 Western Blot Assay: What Determines an Indeterminate Status? Indian Journal of Medical Sciences, 59, 443-450. http://dx.doi.org/10.4103/0019-5359.17051

[8] Owen, S.M., Yang, C., Spira, T., Ou, C.Y., Pau, C.P., Parekh, B.S., et al. (2008) Alternative Algorithms for Human Immunodeficiency Virus Infection Diagnosis Using Tests That Are Licensed in the United States. Journal of Clinical Microbiology, 46, 1588-1595. http://dx.doi.org/10.1128/JCM.02196-07

[9] Grusky, O., Roberts, K.J. and Swanson, A.N. (2006) Communicating Indeterminate Hiv Western Blot Test Results to Clients: An Observational Study of Three Community Testing Sites. AIDS Patient Care STDS, 20, 620-627. http://dx.doi.org/10.1089/apc.2006.20.620

[10] Hecht, F.M., Busch, M.P., Rawal, B., Webb, M., Rosenberg, E., Swanson, M., et al. (2002) Use of Laboratory Tests and Clinical Symptoms for Identification of Primary HIV Infection. AIDS, 16, 1119-1129. http://dx.doi.org/10.1097/00002030-200205240-00005

[11] Henrard, D.R., Phillips, J., Windsor, I., Fortenberry, D., Korte, L., Fang, C., et al. (1994) Detection of Human Immunodeficiency Virus Type 1 p24 Antigen and Plasma RNA: Relevance to Indeterminate Serologic Tests. Transfusion, 34, 376-380. http://dx.doi.org/10.1046/j.1537-2995.1994.34594249046.x

[12] Soroka, S.D., Granade, T.C., Candal, D. and Parekh, B.S. (2005) Modification of Rapid Human Immunodeficiency Virus (HIV) Antibody Assay Protocols for Detecting Recent HIV Seroconversion. Clinical and Diagnostic Laboratory Immunology, 12, 918-921.

[13] Doran, T.I. and Parra, E. (2000) 25 False-Positive and Indeterminate Human Immunodeficiency Virus Test Results in Pregnant Women. Archives of Family Medicine, 9, 924-929. http://dx.doi.org/10.1001/archfami.9.9.924

[14] Gasasira, A.F., Dorsey, G., Kamya, M.R., Havlir, D., Kiggundu, M., Rosenthal, P.J., et al. (2006) False-Positive Results of Enzyme Immunoassays for Human Immunodeficiency Virus in Patients with Uncomplicated Malaria. Journal of Clinical Microbiology, 44, 3021-3024. http://dx.doi.org/10.1128/JCM.02207-05

[15] Lee, D.A., Eby, W.C. and Molinaro, G.A. (1992) HIV False Positivity after Hepatitis B Vaccination. Lancet, 339, 1060. http://dx.doi.org/10.1016/0140-6736(92)90586-R

[16] Rompalo, A.M., Cannon, R.O., Quinn, T.C. and Hook, E.W. (1992) Association of Biologic False-Positive Reactions for Syphilis with Human Immunodeficiency Virus Infection. The Journal of Infectious Diseases, 165, 1124-1126. http://dx.doi.org/10.1093/infdis/165.6.1124

[17] Watt, G., Chanbancherd, P. and Brown, A.E. (2000) Human Immunodeficiency Virus Type 1 Test Results in Patients with Malaria and Dengue Infections. Clinical Infectious Diseases, 30, 25-29.

[18] Thakral, B., Saluja, K., Sharma, R.R. and Marwaha, N. (2006) Algorithm for Recall of HIV Reactive Indian Blood Donors by Sequential Immunoassays Enables Selective Donor Referral for Counseling. Journal of Postgraduate Medicine, 52, 106-109. 
[19] Boeras, D.I., Luisi, N., Karita, E., McKinney, S., Sharkey, T., Keeling, M., et al. (2011) Indeterminate and Discrepant Rapid HIV Test Results in Couples' HIV Testing and Counselling Centres in Africa. Journal of the International AIDS Society, 14, 18. http://dx.doi.org/10.1186/1758-2652-14-18

[20] Talal, N., Flescher, E. and Dang, H. (1992) Are Endogenous Retroviruses Involved in Human Autoimmune Disease? Journal of Autoimmunity, 5, 61-66. http://dx.doi.org/10.1016/0896-8411(92)90020-Q

[21] Talal, N., Dauphinee, M.J., Dang, H., Alexander, S.S., Hart, D.J. and Garry, R.F. (1990) Detection of Serum Antibodies to Retroviral Proteins in Patients with Primary Sjogren's Syndrome (Autoimmune Exocrinopathy). Arthritis \& Rheumatology, 33, 774-781. http://dx.doi.org/10.1002/art.1780330603

[22] Talal, N., Garry, R.F., Schur, P.H., Alexander, S., Dauphinee, M.J., Livas, I.H., et al. (1990) Conserved Idiotype and Antibodies to Retroviral Proteins in Systemic Lupus Erythematosus. Journal of Clinical Investigation, 85, 1866-1871. http://dx.doi.org/10.1172/JCI114647

[23] Urnovitz, H.B., Sturge, J.C., Gottfried, T.D. and Murphy, W.H. (1999) Urine Antibody Tests: New Insights into the Dynamics of HIV-1 Infection. Clinical Chemistry, 45, 1602-1613.

[24] Vardinon, N., Yust, I., Katz, O., Iaina, A., Katzir, Z., Modai, D., et al. (1999) Anti-HIV Indeterminate Western Blot in Dialysis Patients: A Long-Term Follow-Up. American Journal of Kidney Diseases, 34, 146-149. http://dx.doi.org/10.1016/S0272-6386(99)70121-6

[25] Sethoe, S.Y., Ling, A.E., Sng, E.H., Monteiro, E.H. and Chan, R.K. (1995) PCR as a Confirmatory Test for Human Immunodeficiency Virus Type 1 Infection in Individuals with Indeterminate Western Blot (Immunoblot) Profiles. Journal of Clinical Microbiology, 33, 3034-3036.

[26] Dock, N.L., Kleinman, S.H., Rayfield, M.A., Schable, C.A., Williams, A.E. and Dodd, R.Y. (1991) Human Immunodeficiency Virus Infection and Indeterminate Western Blot Patterns. Prospective Studies in a Low Prevalence Population. Archives of Internal Medicine, 151, 525-530. http://dx.doi.org/10.1001/archinte.1991.00400030077014

[27] Genesca, J., Shih, J.W., Jett, B.W., Hewlett, I.K., Epstein, J.S. and Alter, H.J. (1989) What Do Western Blot Indeterminate Patterns for Human Immunodeficiency Virus Mean in EIA-Negative Blood Donors? Lancet, 28, 1023-1025. http://dx.doi.org/10.1016/S0140-6736(89)91027-1

[28] Jackson, J.B., MacDonald, K.L., Cadwell, J., Sullivan, C., Kline, W.E., Hanson, M., et al. (1990) Absence of HIV Infection in Blood Donors with Indeterminate Western Blot Tests for Antibody to HIV-1. The New England Journal of Medicine, 322, 217-222. http://dx.doi.org/10.1056/NEJM199001253220402

[29] Jackson, J.B., Hanson, M.R., Johnson, G.M., Spahlinger, T.G., Polesky, H.F. and Bowman, R.J. (1995) Long-Term Follow-Up of Blood Donors with Indeterminate Human Immunodeficiency Virus Type 1 Results on Western Blot. Transfusion, 35, 98-102. http://dx.doi.org/10.1046/j.1537-2995.1995.35295125746.x

[30] Josephson, S.L., Swack, N.S., Ramirez, M.T. and Hausler Jr., W.J. (1989) Investigation of Atypical Western Blot (Immunoblot) Reactivity Involving Core Proteins of Human Immunodeficiency Virus Type 1. Journal of Clinical Microbiology, 27, 932-937.

[31] Centers for Disease Control and Prevention (2001) Revised Guidelines for HIV Counseling, Testing, and Referral and Revised Recommendations for HIV Screening of Pregnant Women-United States. Morbidity and Mortality Weekly Report, 50, 63-85.

[32] Behets, F., Disasi, A., Ryder, R.W., Bishagara, K., Piot, P., Kashamuka, M., et al. (1991) Comparison of Five Commercial Enzyme-Linked Immunosorbent Assays and Western Immunoblotting for Human Immunodeficiency Virus Antibody Detection in Serum Samples from Central Africa. Journal of Clinical Microbiology, 29, 2280-2284.

[33] Carneiro-Proietti, A.B., Cunha, I.W., Souza, M.M., Oliveira, D.R., Mesquita, N.M., Andrade, C.A., et al. (1999) HIV-(1/2) Indeterminate Western Blot Results: Follow-Up of Asymptomatic Blood Donors in Belo Horizonte, Minas Gerais, Brazil. Revista do Instituto de Medicina Tropical de São Paulo, 41, 155-158. http://dx.doi.org/10.1590/S0036-46651999000300004

[34] Kopko, P., Calhoun, L. and Petz, L. (1999) Distinguishing Immunosilent AIDS from the Acute Retroviral Syndrome in a Frequent Blood Donor. Transfusion, 39, 383-386. http://dx.doi.org/10.1046/j.1537-2995.1999.39499235670.x 